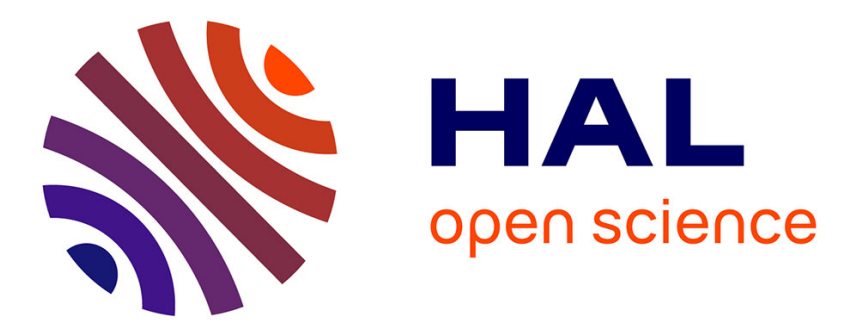

\title{
The Implementation of Traceability in Fashion Networks
}

Laura Macchion, Andrea Furlan, Andrea Vinelli

\section{To cite this version:}

Laura Macchion, Andrea Furlan, Andrea Vinelli. The Implementation of Traceability in Fashion Networks. 18th Working Conference on Virtual Enterprises (PROVE), Sep 2017, Vicenza, Italy. pp.86-96, 10.1007/978-3-319-65151-4_8. hal-01674902

\section{HAL Id: hal-01674902 \\ https://hal.inria.fr/hal-01674902}

Submitted on 3 Jan 2018

HAL is a multi-disciplinary open access archive for the deposit and dissemination of scientific research documents, whether they are published or not. The documents may come from teaching and research institutions in France or abroad, or from public or private research centers.
L'archive ouverte pluridisciplinaire HAL, est destinée au dépôt et à la diffusion de documents scientifiques de niveau recherche, publiés ou non, émanant des établissements d'enseignement et de recherche français ou étrangers, des laboratoires publics ou privés. 


\title{
The Implementation of Traceability in Fashion Networks
}

\author{
Laura Macchion $^{1, *}$, Andrea Furlan ${ }^{2}$ and Andrea Vinelli ${ }^{1}$ \\ ${ }^{1}$ Department of Management and Engineering - University of Padova, Italy \\ \{laura.macchion, andrea.vinelli\}@unipd.it \\ ${ }^{2}$ Department of Economics and Management - University of Padova, Italy \\ andrea.furlan@unipd.it
}

\begin{abstract}
A complete network traceability to identify suppliers and customers' activities and share information along the entire network is not an easy objective to achieve. It requires the involvement of all the network stages: manufacturing, purchasing and distribution processes. This research aims to study traceability for collaborative network within the fashion industry. We conducted an in-depth case study using an interview protocol specifically designed for this research investigating drivers as well as practices for network traceability.
\end{abstract}

Keywords: Fashion, traceability, collaborative networks, supply network configuration, supply chain.

\section{Traceability and the Collaborative Network Context}

Traceability is the ability to trace the history, use and location of a particular entity through the implementation of identification systems (ISO 8402:1994). The ISO 9001:2000 extends this definition to networks' traceability, referring to the ability to trace the history, the use and the location of products and processes along the entire network. This way traceability is related to the origin of raw materials and the history of all processes interesting final products within the network [1]. It involves all purchasing, production and distribution stages, in which processes and product units are appropriately identified by a collaborative exchange of information along the network [2] [3]. Two distinct aspects compose traceability: tracing (i.e. the ability to determine the origin and characteristics of a particular product within the network) and tracking (i.e. the ability to follow the path of a product along the network from suppliers to consumers) [1] [2]. Moreover, two different levels of traceability can be identified. The first is related to company's internal traceability, which is the ability to track and trace the products' batch within firm's boundaries [2]. The second is linked to a broader traceability concept that involves the entire network: network traceability represents the ability to track and trace products' batches along sourcing, production and distribution activities, starting from the raw material till final sale [1]. 
In literature studies mainly focus on agri-food network traceability systems [4] [5] [1] [6], with a particular attention on perishable goods chains such as meat [7], grain [8], fish, fruit [10] and vegetables [3]. However, nowadays, other important sectors such as pharmaceutics are interested in network traceability. Because of the internationalization phenomena that make global networks very difficult to be controlled, also in the fashion industry there is a growing attention to traceability systems to better identify network partners and, in some cases, to protect country of origin strategies. The fashion industry plays a relevant role in the European economy: in 2015 EU fashion industry sales equalled approximately $€ 169$ billion, with 174,000 companies [11] and in particular the Italian fashion industry reached $€ 52.4$ billion with exports representing about the $56 \%$ of the revenue [12].

In recent years some fashion groups have approached the network traceability issue, by focusing specially on the procurement of raw materials. For instance, Patagonia, a manufacture of outdoor clothing, has launched a specific initiative, which allows customers to verify the origin of raw materials used for their products. Despite the growing importance of the network traceability issue for fashion companies, there are no legislations, mandatory requirements or standards identifying the proper method to design a traceability system for collaborative networks. Therefore, companies that decide to implement traceability, face the challenge of creating ad hoc practices. Even the academic literature on fashion traceability appears to be fragmented and limited to some parts of the network. The few contributions available in literature mainly focus on the internal traceability of companies, instead of adopting a network perspective [13] and the alignment with the entire networks, in which many and heterogeneous actors operate, is still a missing point [14].

The achievement of network traceability within the fashion industry needs to be supported by appropriate studies, encompassing the entire network activities to provide relevant value for both companies operating in the collaborative network and customers. This research aims to offer a first contribution in this perspective analysis both drivers and practices in the field of network traceability.

\section{Drivers for Network Traceability}

Achieving network traceability seems to be a current issue for many industries. For instance, because of the scandals occurred in the '90s such as the BSE contamination (Bovine Spongiform Encephalopathy), in the agri-food industry strict network traceability legislation has been introduced to reduce risks for consumer health and minimize costs related to the withdrawal from the market of contaminated batches. Therefore for this industry the traceability of the network is already a legal obligation within the European Union, as well as in other countries such as the United States and Japan, attracting considerable attention of both researchers and practitioners to store real time information along the chain. Such studies have led to the identification of proper techniques to trace final products, and their raw materials, ascertain contamination problems and prevent them [2]. Full compliance with existing legislation is therefore the most important driver for agri-food companies to implement network traceability [15]. 
Nevertheless, other motivations for network traceability exist besides legal and public safety. First, in the fashion industry the development of global networks has increased the attention for sustainability aspects that could be well guaranteed through the implementation of traceability systems [1] [9] [29].

On one hand, production processes that employ chemical components and scarce natural resources, resulting in heavy environmental impacts, characterize the fashion sector. On the other hand, fashion networks are truly planetary, characterized by companies producing and distributing at world-level with different working conditions and Country legislations [19]. Therefore, these aspects encourage the implementation of network traceability to ensure customers the sustainability (both environmental and social) of their network. Second, the network traceability represents a way to provide customers further information about products and processes. Transparency of information becomes a source of competitive advantage that allows companies to differentiate themselves from competitors and build a responsible and reliable brand reputation.

In the fashion world, especially in the luxury segment, country of origin information becomes a guarantee of quality (not only in terms of product quality. but also of social and environmental production conditions). In this way traceability systems represent long-term strategic investment to create consumer confidence, strengthen the company image, and gain a competitive advantage in the market [1] [2]. Third, traceability can also be used to fight fraud in the market [16]. Because of the globalization and the increased use of e-commerce, there has been a strong increase in counterfeit products. Network traceability can be useful in ensuring product authenticity and protecting companies from unfair competition. Counterfeiting can take place at different levels of the chain, from sourcing to customer delivery and different methods (such as holograms, colour-shifting films or inks, sequential product numbering) or tracing technologies (such as RDIF, electronic product codes, barcodes, etc.) have been studied individually by fashion companies to ensure the authenticity of the product [16]. However, a multi-level and dynamic solution that can involve all actors in the network and integrate even different traceability systems is necessary to create an effective anti-counterfeiting mechanism. Fourth, traceability can also be implemented to improve control and communication within complex networks.

A better control of the network could be translated into a reduction in logistics costs (thanks to the reduction of defective products and inventories) and, strengthening cooperation between network partners [17] [1]. Fifth, network traceability allows a better product optimization both in terms of efficiency and quality assurance, by improving the control of network processes. For instance a network traceability system allows to recall only products really affected by quality issues, thus improving process efficiency as well [2] [1]. Sixth, traceability can be a useful tool also to introduce product innovations being a way to facilitate the sharing of improvement proposals among supply chain partners [18].

Finally, companies might choose to implement traceability even in the distribution to geolocalize customers and segment their shopping behaviours [1]. In this way, traceability becomes a way to achieve a strong differentiation in the market. 


\section{Traceability Practices}

The development of traceability for the network still remains an open challenge in the fashion sector. A network traceability system should define the tools and mechanisms to transmit information, the data to be shared, the identification of each product as well as the country of origin of raw materials [4]. The perspective that a network traceability should consider is therefore not only functional, focused on what the system should do, but also organizational, paying attention to the functions and processes composing the system structure [3]. Hence, one of the most critical aspects is the development of a complete inter-organizational traceability that could align different actors and ensure the data exchange in a standardized way.

Two key practices are required for the development of network traceability. First of all, the single Traceability Resource Unit (TRU) (i.e. the individual item or batch to be traced) should be identified [2]. This unit of analysis varies depending on the type of company: for process companies, such as chemical firms, the object to be traced will be the batch; instead product companies, such as the fashion firms, the TRU will be the single product. The TRU evolves along the network as a result of production processes and such transformation must always be documented to guarantee the identification of each step within the network. Therefore the second point interesting the development of traceability practices is represented by the identification of the TRU supported by proper tags, for instance labels, barcodes, microchips or RFID, applied directly to each product or batch or indirectly by fixing the tag on pallets. To each TRU is assigned a code, mainly alphanumeric, with a unique and shared meaning for all actors in the network.

The sharing of product coding with all the actors in the supply chain is therefore a focal point, requiring chain partners to be responsible for the reliability of data provided [2]. Production, movements and storage activities for each TRU will be thus mapped and monitored by all supply partners sharing traceability data [3]. In any case the traceability practices to be implement in the network are strongly subject to specific constraints. In fact the most appropriate traceability system should be identified in accordance to technological and cost constraints, data accuracy possibilities, and reliability of network actors, thus requiring a study of the possibilities of the specific network.

\section{Research Objectives}

Previous studies mainly analysed traceability based on a single company or have analyzed the traceability issue applied to the entire network in sectors where the network traceability is set by regulations, for instance in the food networks [1]. However, other contexts in which actors decide to implement network traceability based on a voluntary decision require further insights. This research investigates this issue,considering the design and the implementation of a voluntary network traceability within the fashion industry,,from raw materials till the end customers and across different supply partners. In particular, fashion industry-specific drivers 
that led companies to adopt network traceability systems and best practices for network traceability are investigated. The following research questions are investigated:

RQ1: Considering that traceability in the fashion industry is still and mainly a voluntary application, what are the drivers that can encourage the implementation of traceability systems within fashion collaborative networks?

RQ2: What traceability practices are developed in fashion collaborative networks?

\section{Methodology}

Considering the explorative nature of the research questions the case study method is adopted [20], since it allows achieving a high level of understanding with observations and in-depth case study is particularly encouraged for the study of contemporary events within their real-life context since it it increases the external validity of results [21] [20].

The case study methodology is appropriate when the research is exploratory and the phenomenon under investigation is still poorly studied, as it offers the opportunity to achieve in-depth results through direct experience [20]. In setting the eligibility criteria for the case study, the selection included a company that: i) operate in the fashion industry; ii) are headquartered in Italy; iii) have international production and distribution networks (to include a company that have to address different environmental and social international regulations within their SCM); iv) is brand owners (thus they have the control of their whole SCM).

The organization involved in this research is one of the leading and most representative companies (in terms of turnover and number of employees) of the fashion system producing leather goods, footwear, clothing and accessories. We selected this company for theoretical reasons [22] [23]: the selected case is recognized as exemplar [21] in the fashion industry and it is undertaking an important voluntary project of network traceability for its leather products, involving from third-tier suppliers till final consumers. We interviewed multiple key informants of the company and its suppliers. In particular, we organized with multiple interviewers many meetings with each network partner to cover the entire network traceability issues, achieve a higher level of reliability [20] and enhance the construct validity [23].

To ensure the validity of the collected data senior managers were involved in the research. We interviewed Chief of Sustainability Officer and specialists of the ICT function of the focal company; CEO and COO of slaughterhouse- $3^{\text {rd }}$ tier supplier; $\mathrm{CEO}$ and $\mathrm{COO}$ of hide collector- $2^{\text {nd }}$ tier; CEO, CSO, Quality Manager and ImportExport manager of the tannery- $1^{\text {st }}$ tier; entrepreneurs, CEOs and specialists of selected façonniers. For triangulation requirements, internal documents provided of network partners were also analysed. Moreover, we had the possibility to visit and have direct observations of all network partners' plants to verify how traceability 
systems were implemented. Data collection phase took place from February 2013 to December 2013, and was supported by multiple investigators to reduce bias and enhance reliability [23]. A semi-structured interview protocol was specifically designed for this research [20], including questions concerning the traceability practices and drivers. All the interviews were recorded and then transcribed [21]. For every network actors, we stopped the number of interviews when we reached data saturation [22] [20]. Finally, a case summary report were then prepared and reviewed by the research team to improve validity [21].

\section{Findings}

For what concerns main drivers (RQ1) leading to undertake a network traceability project, the research highlights that several traceability drivers already recognized in other sectors are confirmed also in fashion networks. In particular, the journey towards a traced network was moved by the desire of responding to sustainability pressures from the final markets and from NGOs (i.e. Greenpeace), which are raising always-higher attention towards the provenience of the raw materials and the Countries in which the different activities processes are executed [31]. Gaining comprehensive knowledge on all the partners involved in the supply activities and identifying the different Countries in which every supplier works are company's needs to be able to comply with local laws and have high assurance that processes and workers' conditions are environmental- (i.e. the use of dangerous chemicals during tannery and production stages) and social- (i.e. labour conditions) friendly [24]. Moreover, in the long term the studied company wants to develop a green brand reputation and this goal starts from being unassailable on all network stages through a complete transparency over its processes and suppliers. This network transparency is considered a potential source of competitive advantage, by ensuring the improvement of the perceived quality of the made in effect.

Another strong motivation encouraging fashion companies to invest efforts on traceability project is related to the enhancement of network control and communication to improve the quality of products and components. In fact, the ability to identify the partners taking part in the development of a finished bag, and the related possibility of quickly identifying which partners are affected by quality problems once that a batch is recognized as damaged or not meeting quality standards, was one of the pillars of the network traceability project. However, the achievement of an enhanced control over the raw materials starts from the assumption that a higher level of network communication and integration is requested [17] by stipulating agreements with network partners and developing trust-based relationships for the exchange of data among all the involved actors.

Indeed, one of the drivers of this traceability project was the need to expand the already-existing transactional relations with suppliers to more collaborative ones. Company managers also wished to develop a traceability system useful to control the possible counterfeiting of raw materials and final products: as the products pertaining to the luxury fashion segment, positioned on a high price range, it is strongly critical to ensure the customer about the authenticity of the product and its 
components.

Moreover, the decision to start a network traceability project was driven by the necessity to refine marketing strategies and in particular to improve the customer geo-location. The application of a RFID tag on every finished product was the final solution implemented to realize this need. Differently from the literature in other industries, the system was not moved by legislation requests: in fact, there are no regulations that impose the adoption of a traceability procedure in the fashion sector, but anyway the analysed firm recognized the need to develop this system to proactively align itself to emerging new market needs.

As for the traceability practices within the fashion network (RQ2), food traceability practice were studied, and subsequently those practices were properly applied to the fashion network composed of many actors (i.e. farmers, slaughterhouses, hide collectors, tanneries, focal company, façonniers, logistic providers and retailers) and of many transformation points in which the raw materials can be joined, transferred, separated or assembled together. These transformation points can lead to relevant problems for traceability purposes [15]. In fact, in the case of foodstuffs, raw materials are often processed directly within one plant without any movements that could damage their healthiness. Below will be analyzed in detail the results to implement traceability with each fashion network partner.

Fourth-tier: Farmer. Traceability of livestock at the farms is already adopted: to trace every domestic animal the European food regulations require very strict traceability procedures composed by two ear-tags (with a tracking number), an electronic subcutaneous microchip, a passport containing animal tracking number and the development of an online database with all the information about animals life (for instance vaccinations, etc.) that are also registered within the passports.

Third-tier supplier: Slaughterhouse. Thanks to the collaboration with the food sector for which traceability of meat is required by legislation for healthy reason, until the skinning process the traceability of hides is guaranteed. But after it a critical traceability point emerges: by regulation only the meat is labelled and traced through all the downstream steps, where on the contrary hides traceability is not mandatory. To ensure traceability after this point, each hide has been identified by a plastic barcode label. This way all information related to the animal can be maintained. Hides can be then processed through a code scanner and sent to the hide collector with a shipping batch code linked to all the coded hides. Thanks to this traceability code, the hides can be separated based on the hides' country of origin since quality problems in the leather of final products comes from animals' country of origin.

Second-tier supplier: Hide collector. Since every hide is marked with a plastic label, traceability within processes of the hide collector (i.e. the actor within the network responsible for the quality leather selection) is preserved. Then, the shipping batch for the tannery is prepared: a new code, the shipping batch code, is generated by the hide collector and is linked to the previous plastic barcode. In this way it is always preserved the network information. As in the previous point, it is fundamental to prepare shipping batches based on the country of origin, for quality reasons.

First-tier supplier: Tannery. From this stage in the network the plastic code 
applied on every hide must be removed, since tannery processes are extremely aggressive and might delete the same code. Moreover, at this point the unit traced becomes the batch composed by many hides that are processed by the tanneries at the same time: all hides coming from the same farmer are processed in the same batch. Even if this means the loss of information on the single hide, this solution is suitable to reach the network traceability objectives, because it is always possible to obtain in every step of tannery process relevant data for network traceability (such as information related to the farmer from which animals come from). For what concerns traceability procedures within the tannery, information could be always traced using a code system that connects shipping batches and production processes. Once again, the information related to the country of origin of batches are guaranteed.

The focal firm and its façonniers. Thanks to the implementation of a web ICT solution to share real time information with façonniers, the focal company is able to trace the hides' information during manufacturing processes. The batches shipped by the tannery are codified and registered in the web ICT system. When the focal company sends the batches to façonniers for the production processes, it assigns a proper code of production, which identifies the tannery information and the specific façonnier where the leather will be processed. This code is traced during all the production processes. After the manufacturing activities, every finished product is then associated with a RFID tag, which contains a serial number associated to all network information (such as production code, tannery's shipping code, etc).

From the focal firm to the retail store. Thanks to the RFID tag, traceability at single bag level can be guaranteed beyond this point till the end customer, since the tag can hold also distribution data, such as the store where the bag is shipped.

All in all, given the different network actors involved in the traceability project and their different internal traceability procedures, it was necessary to standardize data coding procedure to allow data to flow downstream, without interrupting the production workflow [25]. All critical points among network partners were connected using proper code numbers that could provide and ensure all data concerning the farmer, the hide collector, the tannery, the focal company, the façonniers and retail stores. As suggested by literature, every single traceability resource unit (TRU) was identified, coded and physically separated from others to guarantee proper identification [2] [3].

\section{Conclusions}

The study revealed that the drivers that moved the analysed fashion company toward the development of a traceability system were sustainability, product optimization, chain control and communication, counterfeit and competitive advantage reasons. All in all, if in the agri-food chain the protection of consumers' health is the main driver for traceability, in the fashion industry traceability is still seen as a source of an innovative market advantage, able to distinguish a network from competitors. Indeed, in the fashion industry the implementation of network traceability is 
considered a formidable strategy to better control partners [17]. Moreover, the ability to demonstrate the origin of raw materials and products responds to the need for transparency of environmental aspects, such as the use of dangerous chemicals during production stages, and social aspects, such as labour conditions [1].

Although drivers can be different [30], this research shows that practices used for the implementation of a network traceability in the agri-food sector can be applied to the fashion industry. However, strong collaboration is required for their application to share sensitive data. Accordingly to the literature [4][2][15][5][3] the case study highlights that to achieve network traceability some important aspects should be considered: 1. The identification of which products are involved in traceability practices; 2 . The data to be collected, shared along the entire network and then transmitted to customers; 3 . The ICTs required within the network for traceability.

This study shows how traceability is strongly related to the network coordination and integration. An effective network traceability is based on the exchange of relevant information between actors. Along this vein, proper network coordination and integration mechanisms should be developed to implement a traceability project and achieve the elimination of inter-organizational barriers. Information regarding finished products are not stored only at the single firm level, but are collected by every actor of the network and then shared to the downstream partners, requiring a high level of alignment and collaboration among all network partners. In this way products and information can be traced from raw materials till final consumers [26].

Moreover, the development of network traceability involves very high costs that only through collaboration between all actors of the network can be supported. According to a sustainability point of view, network traceability allows the implementation of both environmental and social policies, through the effective control of the entire network, in particular of raw materials' suppliers and façonniers [27]. In fact, customers are sensitive about Countries of origin of products and raw materials: some Countries do not have any laws to avoid cruel practices during slaughter processes, and thanks to many NGOs this critical situation and the related sustainability issues are reaching more and more interest by media. Achieving a complete network traceability within all production steps enhance the sustainability profile and ensure the transparency of production and sourcing processes that, starting from an animal, leads to the production and distribution of finished leather products. Unexpectedly, the case study also shows that after the implementation of the traceability project, the company noticed an effective improvement in quality and innovation of products too, thanks to the better alignment with suppliers [28]. Through the development of a network traceability, the company is able to protect very distinctive and particular "made in" competencies [17] that could improve and increase the perceived product quality, based on the Country of origin effect. Moreover, customers are guaranteed about the authenticity of the product they are buying: the improved control along the entire network disincentive not authorised parallel markets, contributing to fight against counterfeiting [16].

From an academic point of view this research contributes to the OM debate on network traceability by adapting food-industry traceability practices to the fashion industry. First we identified the main drivers that lead a fashion company - which is not forced by regulation - to develop a traceability system. Second, we identified the practices that should be adopted to meet network traceability. Despite network 
traceability have been designed for other industries (e.g. for agri-food contexts), the main best practices can be efficaciously applied also within the fashion industry.

Our research has also implication for practitioners. We detailed the development of a project for network traceability that could be applied by other actors within the fashion leather industry. In particular we developed a system to connect traceability data across network partners, overcoming the problem of loss of traceability data on the single hide from the tanneries. The main limitation of our research is to rely on a single case study, even if in-depth. The analysis could be extended to a broader number of cases in the fashion industry. Besides, the selected case is a very large company, which has high commercial power on its supplier. The results may be different in the case of an SME as a focal company that wants to implement a traceability system within its network. Further studies may also consider the consumer's voice to verify how much traced products are appreciated and then understand if this feature will become a strong order-winner within the fashion system.

Finally, to enhance the debate in the network traceability field future work could deepen the differences between different industries (such as the food and the fashion sector) by considering the drivers and practices implemented.

\section{References}

1. Karlsen, K.M., Dreyer, B., Olsen, P., Elvevoll, E.O.: Literature review: Does a common theoretical framework to implement food traceability exist?, Food Control, 32, 409-417 (2013).

2. Bechini, A., Cimino, M., Marcelloni, F., Tomasi, A.: Patterns and technologies for enabling supply chain traceability through collaborative e-business. Information and Software Technology, 50, 342-359 (2008).

3. Hu, J., Zhang, X., Moga, L., Neculita, M.: Modeling and implementation of the vegetable supply chain traceability system. Food Control, 30, 341-353 (2013).

4. Regattieri, A., Gamberi, M., Manzini, R.: Traceability of food products: General frame work and experimental evidence. Journal of Food Engineering, 81, 347-356 (2007).

5. Bendaoud, M., Lecomte, C., Yannou, B.: A Methodological Framework to Design and Assess Food Traceability Systems. International Food and Agribusiness Management Review, 15 (1), 103-125 (2012).

6. Bosona, T., Gebresenbet, G.: Food traceability as an integral part of logistics management in food and agricultural supply chain. Food Control, 33, 32-48 (2013).

7. Smith, G., Pendell, D., Tatum, J., Belk, K., Sofos, J.: Post-slaughter traceability. Meat Science 80, 66-74 (2008).

8. Thakur, M., Hurburgh, C.: Framework for implementing traceability system in the bulk grain supply chain. Journal of Food Engineering, 95, 617- 626 (2009).

9. Da Giau, A., Macchion, L., Caniato, F., Caridi, M., Danese, P., Rinaldi, R., Vinelli, A. Sustainability practices and web-based communication: An analysis of the Italian fashion industry. Journal of Fashion Marketing and Management, 20(1), 72-88 (2016). 
10. Canavari, M., Centonze, R., Hingley, M., Spadoni, R.: Traceability as part of competitive strategy in the fruit supply chain. British Food Journal, 112(2), 171-186 (2010).

11. Euratex, (2017), http://euratex.eu/press/key-data/, accessed in March 2017.

12. Sistema Moda Italia: http://www.sistemamodaitalia.com/it/press/noteeconomiche/item/9875-consuntivo-2015-e-outlook-2016, accessed in March 2017.

13. Bottani, E., Rizzi, A.: Economical assessment of the impact of RFID technology and EPC system on the fast-moving consumer goods supply chain. International Journal of Production Economics, 112(2), 548-569 (2008).

14. Macchion, L., Danese, P., Vinelli, A. Redefining supply network strategies to face changing environments. A study from the fashion and luxury industry. Operations Management Research, 8(1-2), 15-31 (2015).

15. Donnelly, K., Karlsen, K., Olsen, P.: The importance of transformations for traceability. - A case study of lamb and lamb products. Meat Science, 83, 68-73 (2009).

16. Li, L., (2013): Technology designed to combat fakes in the global supply chain. Business Horizons, 56, 167-177.

17. Guercini, S., Runfola, A.: The integration between marketing and purchasing in the traceability process. Industrial Marketing Management, 38, 883-891 (2009).

18. Macchion, L., Moretto, A., Caniato, F., Caridi, M., Danese, P., Spina, G., Vinelli, A. Improving innovation performance through environmental practices in the fashion industry: the moderating effect of internationalisation and the influence of collaboration. Production Planning \& Control, 28(3), 190-201 (2017).

19. Macchion, L., Fornasiero, R., Vinelli, A. Supply chain configurations: a model to evaluate performance in customised productions. International Journal of Production Research, 55(5), 1386-1399 (2017).

20. Voss, C., Tsikriktsis, N., Frohlich, M.: Case research in operations management. International Journal of Operations \& Production Management, 22(2), 195-219 (2002).

21. Yin, R.K., Case Study Research: Design and Methods, 2nd Edition. Sage, Thousand Oaks, CA (1994).

22. Eisenhardt, K.M.: Building theories from case study research. Academy of Management Review, 14 (4), 532-550 (1989).

23. Eisenhardt, K.M., Graebner, M.E: Theory building from cases: Opportunities and challenges. Academy of management journal, 50(1), 25-32 (2007).

24. New, S.: The transparent supply chain. Harvard Business Review, 88, 1-5 (2010).

25. Bevilacqua, M., Ciarapica, F.E., Giacchetta, G.: Business process reengineering of a supply chain and a traceability system: A case study. Journal of Food Engineering, 93, 13-22 (2009).

26. Engelseth, P.: Food product traceability and supply network integration. Journal of Business \& Industrial Marketing, 24(5/6), 421-430 (2009).

27. Zhu, Q., Sarkis, J., Geng, Y.: Green supply chain management in China: pressures, practices and performance. International Journal of Operations \& Production Management, 25(5), 449-468 (2005).

28. Papetti, P., Costa, C., Antonucci, F., Figorilli, S., Solaini, S., Menesatti, P.: A RFID webbased infotracing system for the artisanal Italian cheese quality traceability. Food Control, 27(1), 234-241 (2012).

29. Fornasiero, R., Brondi, C., Collatina, D.: Proposing an integrated LCA-SCM model to evaluate the sustainability of customisation strategies (2017). 
30. Fiorentin, E., Contiero, E.: Analysing the features of modules and interfaces across the small consulting firms. In 5th World Conference on P\&OM, Havana, (2016).

31. Lion, A., Macchion, L., Danese, P., Vinelli, A. Sustainability approaches within the fashion industry: the supplier perspective. In Supply Chain Forum: An International Journal (Vol. 17, No. 2, pp. 95-108). Taylor \& Franci) (2016). 